\title{
Effects of acute hypoventilation and hyperventilation on exhaled carbon monoxide measurement in healthy volunteers Franco Cavaliere*1, Carmen Volpe ${ }^{1}$, Riccardo Gargaruti ${ }^{1}$, Andrea Poscia ${ }^{2}$, Michele Di Donato², Giovanni Grieco ${ }^{2}$ and Umberto Moscato ${ }^{2}$
}

Address: ${ }^{1}$ Institute of Anaesthesia and Intensive Care, Catholic University of the Sacred Heart, Rome, Italy and ${ }^{2}$ Institute of Hygiene, Catholic University of the Sacred Heart, Rome, Italy

Email: Franco Cavaliere* - f.cavaliere@rm.unicatt.it; Carmen Volpe - volpe.carmen@libero.it; Riccardo Gargaruti - riccardo.gargaruti@libero.it; Andrea Poscia - andreaposcia@libero.it; Michele Di Donato - michele.didonato@edu.rm.unicatt.it; Giovanni Grieco - giovanni.grieco@ieo.it; Umberto Moscato - umoscato@rm.unicatt.it

* Corresponding author

Published: 23 December 2009

BMC Pulmonary Medicine 2009, 9:5 I doi:10.1 I86/I47|-2466-9-5 I
Received: I May 2009

Accepted: 23 December 2009

This article is available from: http://www.biomedcentral.com/I47/-2466/9/5 I

(c) 2009 Cavaliere et al; licensee BioMed Central Ltd.

This is an Open Access article distributed under the terms of the Creative Commons Attribution License (http://creativecommons.org/licenses/by/2.0), which permits unrestricted use, distribution, and reproduction in any medium, provided the original work is properly cited.

\begin{abstract}
Background: High levels of exhaled carbon monoxide $(\mathrm{eCO})$ are a marker of airway or lung inflammation. We investigated whether hypo- or hyperventilation can affect measured values.

Methods: Ten healthy volunteers were trained to achieve sustained end-tidal $\mathrm{CO} 2$ (etCO2) concentrations of 30 (hyperventilation), 40 (normoventilation), and $50 \mathrm{mmHg}$ (hypoventilation). As soon as target etCO2 values were achieved for $120 \mathrm{sec}$, exhaled breath was analyzed for eCO with a photoacoustic spectrometer. At etCO2 values of 30 and $40 \mathrm{mmHg}$ exhaled breath was sampled both after a deep inspiration and after a normal one. All measurements were performed in two different environmental conditions: $\mathrm{A}$ ) ambient $\mathrm{CO}$ concentration $=0.8 \mathrm{ppm}$ and $\mathrm{B}$ ) ambient $\mathrm{CO}$ concentration $=1.7 \mathrm{ppm}$.
\end{abstract}

Results: During normoventilation, eCO mean (standard deviation) was 11.5 (0.8) ppm; it decreased to $10.3(0.8) \mathrm{ppm}$ during hyperventilation $(\mathrm{p}<0.0 \mathrm{I})$ and increased to II.9 $(0.8) \mathrm{ppm}$ during hypoventilation $(\mathrm{p}<0.0 \mathrm{I})$. eCO changes were less pronounced than the correspondent et $\mathrm{CO}_{2}$ changes (hyperventilation: $10 \%$ Vs $25 \%$ decrease; hypoventilation $3 \% \mathrm{Vs} 25 \%$ increase). Taking a deep inspiration before breath sampling was associated with lower eCO values $(p<0.01)$, while environmental $\mathrm{CO}$ levels did not affect eCO measurement.

Conclusions: eCO measurements should not be performed during marked acute hyperventilation, like that induced in this study, but the influence of less pronounced hyperventilation or of hypoventilation is probably negligible in clinical practice

\section{Background}

In the human body, carbon monoxide (CO) has two origins: the exogenous source is the absorption from tobacco smoke and polluted air, the endogenous one is the breakdown of heme molecules by heme oxidase (HO) $[1,2]$.
Exogenous $\mathrm{CO}$ increases in relation with the exposure to tobacco smoke and polluted air. Endogenous CO grows in the case of increased heme catabolism, caused by hemolysis, or by the synthesis of the isoenzyme HO-1, also known as stress-inducible heat shock protein 32, 
which is upregulated by a variety of stressors, such as cytokines, hypoxia, and reactive oxygen species. In all cases, the increased $\mathrm{CO}$ in the body results in increased $\mathrm{CO}$ levels in exhaled breath (eCO). Consequently eCO measurements may be useful to evaluate smoking abstinence [3], exposition to polluted air [4], oxidative stress caused by anaesthesia or surgery [5], severe sepsis [6], stable asthma and asthma exacerbations $[7,8]$, chronic obstructive pulmonary disease (COPD) [9], hemolysis in children with sickle cell disease [10], and upper [11] and lower airway inflammation [12]. Table 1 reports some examples of eCO levels in smoking healthy subjects and patients with significant issues.

Independently from the amount of $\mathrm{CO}$ produced by a patient, his/her eCO levels may be influenced by the condition in which measurements are performed. For instance eCO can temporarily increase during oxygen therapy because hyperoxia facilitates $\mathrm{CO}$ release from carboxyhemoglobin [13-15]. Acute hyperventilation may decrease eCO values by dilution; in addition theoretical models suggest that alveolar ventilation may affect $\mathrm{CO}$ stores by varying the partial pressure of this gas in the alveoli and consequently in blood and tissues. In that case a proportionate amount of $\mathrm{CO}$ should be released or stored in order to achieve a new equilibrium [16]. This process can take several hours, meanwhile eCO measures may be poorly representative of $\mathrm{CO}$ production.

Changes of ventilatory pattern can potentially occur near eCO measurements. Patients can be induced to hyperventilate by the procedure of breath sampling itself [17]; furthermore, acute ventilatory changes are not infrequent in asthma exacerbations, sepsis, or during assisted mechanical ventilation. The aim of this study was to evaluate whether acute hypo- or hyperventilation can affect eCO measurements. Secondarily, we evaluated the influence of environmental $\mathrm{CO}$ and breath sampling procedure on eCO measurements.

\section{Methods}

The study was carried out in the Catholic University of the Sacred Heart in Rome. Measurements were performed in duplicate in two laboratories situated in different buildings, the first one in the Surgical Intensive Care Unit (A), the second in the institute of Hygiene (B). After the approval of local Ethic Committee and informed consent, 10 healthy volunteers (5 men and 5 women) were enrolled in the study. Table 2 reports theirs anthropometric and lung functions values.

Exclusion criteria were: a) active or passive tobacco smoke, b) chronic respiratory diseases, and c) acute respiratory diseases occurred in the past four months.

In each subject, eCO was measured at end tidal $\mathrm{CO}_{2}$ $\left(\mathrm{etCO}_{2}\right.$ ) values of 30,40 , and $50 \mathrm{mmHg}$ in $\mathrm{A}$ and B settings. At et $\mathrm{CO}_{2}$ values of 30 and $40 \mathrm{mmHg}$, exhaled gases were collected both after normal inspiration and after maximum inspiration. Measurements at $50 \mathrm{mmHg}$ were only performed after normal inspiration in order to avoid a brisk et $\mathrm{CO}_{2}$ decrease. Measurement were performed twice in each setting.

Subjects were asked to breath through a mouth piece in a device (figure 1) including a) a HME bacterial/viral filter (DAR Barrierbac S, Mallinkrodt DAR, Italy); b) the cell of the main stream capnometer CosmoPlus mod. 8100 (Novametrix Medical Systems Inc. Connecticut, USA) in order to measure et $\mathrm{CO}_{2} ; \mathrm{c}$ ) a tracheal tube (Mallinkrodt Inc, UK) with an internal diameter of $9 \mathrm{~mm}$ in order to prevent any risk of collecting external air during sampling for eCO measurements. The HME filter (internal volume $35 \mathrm{~mL}$ ) protected the capnometer cell from condensation

Table I: Exhaled CO levels in smoking healthy subjects and patients with significant issues.

\begin{tabular}{|c|c|c|c|c|}
\hline \multirow[t]{2}{*}{ Authors } & \multirow[t]{2}{*}{ Diseases or smoking } & \multicolumn{2}{|c|}{ Exhaled CO level (ppm) } & \multirow[t]{2}{*}{ N. Subjects } \\
\hline & & Mean & Range or S.D. or $95 \%$ C.I. & \\
\hline Deveci et al (2004) [27] & Smoking & 17.13 & \pm 8.5 & 243 \\
\hline Carpagnano et al (2003)[28] & Smoking & 16.70 & \pm 5.5 & 31 \\
\hline Montuschi et al. (200I) [9] & COPD & 7.40 & \pm 1.9 & 15 \\
\hline Montuschi et al. (200I) [9] & COPD + Smoking & 20.0 & \pm 2.6 & 15 \\
\hline Biernacki et al (200I) [12] & LRTI & 5.20 & \pm 0.5 & 35 \\
\hline Yamaya et al (1998) [29] & URTI & 5.60 & \pm 0.4 & 20 \\
\hline Ohara $Y$ et al (2006) [7] & Asthma & 5.10 & \pm 0.4 & 22 \\
\hline Kiyoshi et al (1997) [30] & Asthma & 5.60 & \pm 0.6 & 12 \\
\hline Paredi et al (1999) [31] & $\mathrm{CF}$ & 6.70 & \pm 0.6 & 29 \\
\hline Horvath et al. (2003) [32] & Bronchiectasis & 5.00 & $3.0-15.0$ & 31 \\
\hline De Las Heras et al (2003) [33] & SBP & 7.00 & \pm 0.5 & 9 \\
\hline
\end{tabular}

COPD chronic obstructive pulmonary disease; LRTI lower respiratory tract infection; URTI upper respiratory tract infections; CF cystic fibrosis; SBP spontaneous bacterial peritonitis; 
Table 2: Anthropometric and lung function values as means (standard deviations) of the healthy volunteers enrolled in this study.

\begin{tabular}{|c|c|c|}
\hline & Men & Women \\
\hline AGE (anni) & $31.40(12.30)$ & $28.60(12.20)$ \\
\hline BMI $\left(\mathrm{Kg} / \mathrm{m}^{2}\right)$ & $24.19(1.41)$ & $20.88(3.10)$ \\
\hline FEV $_{\text {I }}(\mathrm{L})$ & $3.76(0.40)$ & $2,62(0.64)$ \\
\hline FVC (L) & $4.23(0.48)$ & $3.02(0.67)$ \\
\hline FEV $/$ FVC (\%) & $88.95(1.85)$ & $86.57(2.10)$ \\
\hline PFER (L/s) & $8.57(0.96)$ & $5.32(1.33)$ \\
\hline
\end{tabular}

BMI body mass index; FEV , forced expiratory volume in one second; FVC forced vital capacity; FEV / FVC forced expiratory volume in one second/forced vital capacity; PEFR peak expiratory flow rate;

and allowed gas sampling for eCO measurements from the capnometry port. Initially, subjects were trained: a) to perform a prolonged expiration that lasted not less than 16 seconds, and b) to hypoventilate or hyperventilate in order to maintain a target et $\mathrm{CO}_{2}$ value on the display of the capnometer. Successively, they were asked to achieve the et $\mathrm{CO}_{2}$ values of 30,40 , and $50 \mathrm{mmHg}$ in random sequence. As soon as the target et $\mathrm{CO}_{2}$ value was maintained within a range of $\pm 2 \mathrm{mmHg}$ for $120 \mathrm{sec}$, the patients were asked to perform a prolonged expiration and exhaled gases were sampled for eCO analysis.

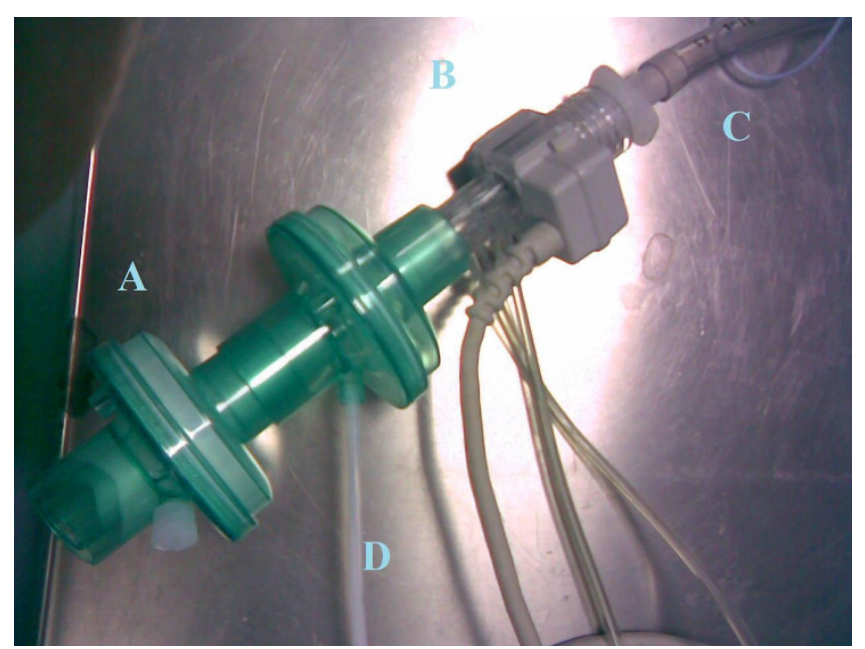

Figure I

The device assembled for breath sampling and etCO $\mathrm{O}_{2}$ measurement. The HME filter $(\mathrm{A})$; the cell of the main stream capnometer CosmoPlus mod. 8100 (Novametrix Medical Systems Inc. Connecticut, USA) in order to measure etCO $\mathrm{CO}_{2}(\mathrm{~B})$; a Mallinkrodt tracheal tube with an internal diameter of $9 \mathrm{~mm}$ in order to prevent any risk of collecting external air during sampling for eCO measurements (C). The tube I $\mathrm{m}$ long and with an internal diameter of $3 \mathrm{~mm}$ through which breath samples were suctioned (D).
Breath samples were suctioned through a tube $1 \mathrm{~m}$ long and with an internal diameter of $3 \mathrm{~mm}$ by the photoacoustic spectrometer utilized for $\mathrm{CO}$ analysis; $80 \mathrm{~mL}$ were collected in $10 \mathrm{sec}$. Sampling was started by an operator three seconds after the beginning of a prolonged expiration lasting 16 seconds or more. It was initially assessed with capnography that an interval of two seconds was long enough to avoid anatomical dead space sampling. As a further precaution, the operator looked at the capnogram displayed by Cosmo plus during gas sampling; if sampling started before phase $\mathrm{C}$ (alveolar plateau), the procedure was repeated. The et $\mathrm{CO}_{2}$ value measured before (pre-test et $\mathrm{CO}_{2}$ ) and during (test et $\mathrm{CO}_{2}$ ) each eCO measurements and the peripheral arterial oxygen saturation $\left(\mathrm{SpO}_{2}\right)$ were registered. Before each session of the study, the capnometer was calibrated and environmental CO concentration was measured.

eCO was measured with a photo-acoustic spectrometer field gas monitor Innova 1312 (LumaSense Technologies $\mathrm{A} / \mathrm{S}$, Denmark) equipped with a filter for $\mathrm{CO}$ analysis and with the software 7300 (LumaSense Technologies A/S, Denmark). The instrument is based on the photo-acoustic effect in the infra-red wave-lenghts[18]. Sampled CO absorbs light energy at a specific wave length, emitted by spectrometer, and transforms it into kinetic energy; this process causes local heating and pressure waves resulting in sounds that can be detected by a microphone. The photo-acoustic field gas monitor suctions gaseous samples by a pump to fill the photo-acoustic cell in which measurements are performed. Dead space, water-vapor's (or other gases) and temperature interference were automatically compensated. Detection limit was $\geq 0.02 \mathrm{ppm}$ (part per million), with Sample Integration Times (S.I.T.) fixed at 5 seconds and multiplication factor 1.

The statistical analysis was carried out with the software "Statistica for Windows" (StatSoft Inc, USA) and STATA Intercooled v. 9.2 software for MacIntosh (Stata Co.; College Station Lakewag, TX, USA). Values are reported as means (standard deviations). Major deviations from normal distribution were ruled out by graphic inspection and by Shapiro-Wilks's test. The Kruskal-Wallis (K-W) equality-of-populations rank test (adjusted with Bonferroni at level of significance $\mathrm{p} \leq 0.05$ ) was employed to assess real difference of variation between lab A vs lab B.

Statistical analysis on eCO values was performed with ANOVA for repeated measures; planned comparisons were tested with linear contrasts. Factors taken into account were setting (lab A Vs B) and etCO ( $^{2}$ V Vs 40 Vs $50 \mathrm{mmHg}$ ); planned comparisons were hypoventilation Vs normoventilation, hyperventilation Vs normoventilation, normal inspirations Vs deep inspiration. ANOVA for repeated measures was also applied to $\mathrm{SpO} 2$ values. The 
factor taken into account was et $\mathrm{CO}_{2}$; planned comparisons were hypoventilation Vs normoventilation and hyperventilation Vs normoventilation. Finally, pre-test and test et $\mathrm{CO}_{2}$ values were compared with paired t-test.

\section{Results}

eCO analysis showed a good level of reproducibility. The mean difference between duplicate measurements was $0.11(0.20) \mathrm{ppm}$. Environmental CO concentration was $0.8 \mathrm{ppm}$ in lab A and $1.7 \mathrm{ppm}$ in lab B.

eCO values are reported in table 3 . In comparison with normoventilation, eCO values were lower during hyperventilation and higher during hypoventilation $(\mathrm{p}<0.01$ in both cases); difference was more pronounced between normo- and hyperventilation (mean value: $1.2 \mathrm{ppm}$ ) than between normo- and hypoventilation (mean value: 0.4 $\mathrm{ppm})$. No significant difference was observed between measurements performed in lab A and B (K-W test), while measured eCO levels were significantly lower when gas sampling was performed after a deep inspiration than after a normal inspiration $(\mathrm{p}<0.01)$.

Table 4 reports $\mathrm{SpO}_{2}$ and et $\mathrm{CO}_{2}$ values. In comparison with normoventilation, $\mathrm{SpO}_{2}$ increased during hyperventilation and decreased during hypoventilation $(\mathrm{p}<0.01$ in both cases). Test et $\mathrm{CO}_{2}$ registered during the prolonged expiration for gas sampling were significantly higher than pre-test etCO ${ }_{2}(\mathrm{p}<0.01)$.

\section{Discussion}

In general ventilation patterns can influence quantification of volatile analytes in exhaled breath and should be controlled to ensure representative analyses [17]. In this study we evaluated whether acute hypo- or hyperventilation can significantly influence eCO measurements. This hypothesis was only partially confirmed because hyperventilation decreased eCO, but to a much lesser extent than et $\mathrm{CO}_{2}$; in practice, eCO decreased by $10 \%$ while et $\mathrm{CO}_{2}$ decreased by $25 \%$. Hypoventilation had an even lesser effect, causing a small and clinically negligible eCO increase $(3 \%)$ while et $\mathrm{CO}_{2}$ increased by $25 \%$. We also found that eCO measurements were not affected by envi- ronmental $\mathrm{CO}$, but decreased slightly if a deep inspiration is taken before breath sampling.

Changes of ventilatory pattern are common in patients affected by respiratory diseases, particularly during mechanical ventilation; in addition, the procedure of breath sampling itself may induce patients to hyperventilate [17]. Acute hypo- and hyperventilation cause proportional changes of the levels of many analytes, such as $\mathrm{CO}_{2}$, isoprene, and ethane, in exhaled breath [17-19]. By contrast our results point out that hypo- and hyperventilation have small impact on eCO measurements; this is in agreement with the observation reported by other Authors that ventilatory changes affects eCO and etCO ${ }_{2}$ differently [17].

Our results are apparently in contrast with theoretical predictions. In steady state, eCO is strictly correlated with the endogenous production of $\mathrm{CO}$ and with carboxyhaemoglobin blood levels [20], but these relationships are influenced by alveolar ventilation, as well as by the environmental CO levels, by the diffusing capacity of the lung for $\mathrm{CO}$, and by the oxygen partial pressure in pulmonary capillaries [16]. By means of a mathematical model, Cobourn and Coll calculated that doubling alveolar ventilation from 4 to 8 liters per minute in a patient with a normal CO production of $0.42 \mathrm{~mL}$ per hour would have resulted in a $43 \%$ decrease of carboxyhaemoglobin, from 0.37 to $0.21 \%$ [16]; a corresponding variation can be hypothesized for eCO. The smaller changes observed in this study are possibly explained because calculations were referred to the new steady state that may be achieved only several hours after ventilatory variations. Cobourn and Coll estimated that the half-life of the process was about 7 hours [16], far longer than the half-life of $\mathrm{CO}_{2}$ store variations, which have been estimated around 70 minutes or less with animal models $[21,22]$ and around 35 minutes in men [19]. The longer CO half-life may be explained by the small amount of this gas released every minute through the lungs in comparison with the stores in the human body. Stored CO has been estimated at 10 $\mathrm{mL}, 8$ of which are bound to hemoglobin [23]. The CO released by a healthy man is about $0.4 \mathrm{~mL}$ per hours [21]

Table 3: Exhaled carbon monoxide values registered in laboratory $A$ and $B$.

\begin{tabular}{|c|c|c|c|c|c|}
\hline \multirow{2}{*}{$\begin{array}{c}\text { Et- } \mathrm{CO}_{2} \text { target } \\
\text { Inspiration }\end{array}$} & \multicolumn{2}{|c|}{$30 \mathrm{mmHg}$ (hyperventilation) } & \multicolumn{2}{|c|}{$40 \mathrm{mmHg}$ (normoventilation) } & \multirow{2}{*}{$\begin{array}{c}50 \mathrm{mmHg} \text { (hypoventilation) } \\
\text { Normal }\end{array}$} \\
\hline & Normal & Deep & Normal & Deep & \\
\hline Lab A (0.8 ppm) & $10.2(0.9)$ & $9.6(0.8)$ & II.4(0.8) & $10.7(0.8)$ & II.8(0.9) \\
\hline Lab B ( I.7 ppm) & $10.3(0.7)$ & $9.7(0.7)$ & II.6(0.8) & $10.8(0.8)$ & $11.9(0.7)$ \\
\hline Total & $10.3(0.8)$ & $9.7(0.8)$ & $11.5(0.8)$ & $10.8(0.8)$ & $11.9(0.8)$ \\
\hline
\end{tabular}

Means (standard deviations) of exhaled carbon monoxide $(\mathrm{eCO})$ values registered in laboratory A and B (environmental eCO level 0.8 and 1.7 $\mathrm{ppm}$, respectively). Values are reported as particles per milion (ppm) .

Statistical analysis: ANOVA: LabA Vs Lab B non significant; hyperventilation Vs normoventilation $\mathrm{p}<0.0$ I; hyperventilation Vs normoventilation $\mathrm{p}<$ 0.01 ; normal inspiration $V s$ deep inspiration $\mathrm{p}<0.01$. 
Table 4: Exhaled carbon monoxide, end tidal $\mathrm{CO}$, and peripheral oxygen saturation.

\begin{tabular}{|c|c|c|c|c|c|}
\hline \multirow{2}{*}{$\begin{array}{c}\text { Et-CO2 target } \\
\text { Inspiration }\end{array}$} & \multicolumn{2}{|c|}{$30 \mathrm{mmHg}$ (hyperventilation) } & \multicolumn{2}{|c|}{$40 \mathrm{mmHg}$ (normoventilation) } & \multirow{2}{*}{$\begin{array}{c}50 \mathrm{mmHg} \text { (hypoventilation) } \\
\text { Normal }\end{array}$} \\
\hline & Normal & Deep & Normal & Deep & \\
\hline eCO (ppm) & $10.3(0.8)$ & $9.7(0.8)$ & II.5 (0.8) & $10.8(0.8)$ & $11.9(0.8)$ \\
\hline Pre-test etCO $\mathrm{CO}_{2}(\mathrm{mmHg})$ & $29.4(1.6)$ & $28.7(1.6)$ & $39.4(1.7)$ & $39.2(1.7)$ & $49.1(1.7)$ \\
\hline Test etCO $(\mathrm{mmHg})$ & $37.8(2.5)$ & $35.6(2.8)$ & $46.1(3.3)$ & $43.0(2.9)$ & $51.6(3)$ \\
\hline $\mathrm{SpO}_{2}(\%)$ & \multicolumn{2}{|c|}{$99(1)$} & \multicolumn{2}{|c|}{$98(I)$} & $96(2)$ \\
\hline
\end{tabular}

Means (standard deviations) of exhaled carbon monoxide $(\mathrm{eCO})$ values, end tidal $\mathrm{CO}_{2}$ values measured before and during breath sampling (respectively pre-test etCO $\mathrm{C}_{2}$ and test et $\mathrm{CO}_{2}$ ), and peripheral oxygen saturation $\left(\mathrm{SpO}_{2}\right)$.

Statistical analysis. EtCO $\mathrm{E}_{2}$ : pre-test $\mathrm{Vs}$ test $\mathrm{p}<0.01$. $\mathrm{SpO}_{2}$ : ANOVA $\mathrm{p}<0.01$; hyperventilation $\mathrm{Vs}$ normoventilation $\mathrm{p}<0.0 \mathrm{l}$; hyperventilation $\mathrm{Vs}$ normoventilation $\mathrm{p}<0.01$.

i.e. $7 \mu \mathrm{L}$ per minute, which corresponds to about $0.07 \%$ of body stores and $0.09 \%$ of blood content. Conversely, the readily exchangeable $\mathrm{CO}_{2}$ stored in the body is about $14 \mathrm{~L}$ [24] and the $\mathrm{CO}_{2}$ released is about $200-250 \mathrm{~mL}$ per minute, which corresponds to about $1.4-1.8 \%$ of body stores. As a consequence the stabilization of eCO and blood carboxyhemoglobin levels after ventilatory changes requires many hours. Hypothetically, if in this study hypoventilation or hyperventilation had been prolonged for a time interval long enough to approximate the steady state, eCO changes would have possibly shown the same magnitude of etCO ${ }_{2}$ changes.

Our results stress the importance of standardizing the procedure for measuring eCO. We observed that taking a deep or normal inspiration can affect eCO levels, other Authors reported that measuring after a breath hold may result in higher eCO values than sampling without breath hold [25] In addition, our data suggest that, even in healthy subjects, a deep expiration may recruit pulmonary alveoli that are poorly represented in a normal expiration since a significant difference was observed between et $\mathrm{CO}_{2}$ values measured immediately before (pre-test) and during (test) breath sampling. Of note, pulmonary heterogeneity strongly affects the relationship between eCO and CO$\mathrm{Hb},[16]$ which is lost in patients affected by severe pulmonary emphysema or airway obstruction $[20,26]$.
A limit of our study is that we did not evaluate the effects of prolonged ventilatory changes on eCO. In addition, we measured $\mathrm{CO}$ values by a photoacoustic spectrometer. To our knowledge this kind of instrument has not been utilized for eCO measurement before. In this study photoacoustic spectrometer performed CO analysis with very high sensitivity and precision on breath samples that were representative of the entire exhaled breath. Theoretically the eCO values obtained with our method may reflect a wider alveolar population in comparison with the end tidal values provided by electrochemical sensors that are utilized for routine eCO measurements. These methodological differences may partly explain why the volunteers enrolled in this study presented relatively high eCO values for non-smokers compared with literature data (Table 5). Other possible explanations were that all the subjects lived in densely populated urban environment and were consequently exposed to high levels of environmental CO and that eCO values are characterized by large interindividual variability [4]; as a matter of fact, eCO levels similar to those observed in this study have been reported in healthy non smokers by other authors [14].

\section{Conclusions}

While eCO values are scarcely affected by hypoventilation that occurs during measurement, hyperventilation should be avoided because it significantly decreases eCO values.

Table 5: Exhaled carbon monoxide values in non smoking healthy subjects reported in literature.

\begin{tabular}{lccc}
\hline Authors & \multicolumn{2}{c}{ Exhaled CO level (ppm) } \\
\cline { 2 - 3 } & Mean & Range or S.D. or 95\% C.I. \\
\hline Chatkin J. et al. (2007) [3] & 4.30 & \pm 2.5 & 152 \\
Cunnington and Hormbrey (2002) [34] & 1.26 & $1.14-1.37$ & 366 \\
Deveci et al (2004) [27] & 3.61 & \pm 2.15 & 55 \\
Horvath et al. (2003) [32] & 3.00 & $0.5-5.0$ & 37 \\
Laranjeira R. at al (2000) [35] & 2.50 & $1.0-4.0$ & 100 \\
Montuschi et al. (2001) [9] & 3.00 & \pm 0.3 & 10 \\
Scharte et al. (2000) [36] & 1.55 & $1.2-1.7$ & 6
\end{tabular}


Nonetheless light hyperventilation occurring during measurements may be acceptable because eCO changes are much less pronounced than ventilation changes (reflected by etCO $\mathrm{CO}_{2}$ ).

\section{Competing interests}

The authors declare that they have no competing interests.

\section{Authors' contributions}

FC and UM conceived of the study and reviewed the manuscript. RG and MDD were involved with data collection and statistical analysis. CV, GG, and AP drafted the manuscript.

\section{All authors read and approved the final manuscript.}

\section{References}

I. Wu L, Wang R: Carbon monoxide: endogenous production, physiological functions, and pharmacological applications. Pharmacol Rev 2005, 57(4):585-630.

2. Ryter SW, Alam J, Choi AM: Heme oxygenase-I/carbon monoxide: from basic science to therapeutic applications. Physiol Rev 2006, 86(2):583-650.

3. Chatkin J, Fritscher L, de Abreu C, Cavalet-Blanco D, Chatkin G: Exhaled carbon monoxide as a marker for evaluating smoking abstinence in a Brazilian population sample. Prim Care Respir J 2007, 16(1):36-40.

4. Jones AY, Lam PK: End-expiratory carbon monoxide levels in healthy subjects living in a densely populated urban environment. Sci Total Environ 2006, 354(2-3): I50-6.

5. Hayashi M, Takahashi T, Morimatsu H, Fujii H, Taga N: Increased carbon monoxide concentration in exhaled air after surgery and anesthesia. Anesth Analg 2004, 99(2):444-8.

6. Zegdi R, Perrin D, Burdin M, Boiteau R, Tenaillon A: Increased endogenous carbon monoxide production in severe sepsis. Intensive Care Med 2002, 28(6):793-6.

7. Ohara Y, Ohrui T, Morikawa T, He M, Yasuda : Exhaled carbon monoxide levels in school-age children with episodic asthma. Pediatr Pulmonol 2006, 4 I (5):470-4.

8. Montuschi P, Corradi M, Ciabattoni G, Nightingale J, Kharitonov SA Barnes PJ: Increased 8-isoprostane, a marker of oxidative stress, in exhaled condensate of asthma patients. Am J Respir Crit Care Med 1999, 160(I):216-20.

9. Montuschi P, Kharitonov SA, Barnes PJ: Exhaled carbon monoxide and nitric oxide in COPD. Chest 200I, I 20(2):496-50I.

10. Sylvester KP, Patey RA, Rafferty GF, Rees D, Thein SL: Exhaled carbon monoxide levels in children with sickle cell disease. Eur J Pediatr 2005, 164(3): 162-5

II. Andersson JA, Uddman R, Cardell LO: Increased carbon monoxide levels in the nasal airways of subjects with a history of seasonal allergic rhinitis and in patients with upper respiratory tract infection. Clin Exp Allergy 2002, 32(2):224-7.

12. Biernacki WA, Kharitonov SA, Barnes PJ: Exhaled carbon monoxide in patients with lower respiratory tract infection. Respir Med 200I, 95( I 2): I003-5.

13. Zegdi R, Caid R, Louw A Van De, Perrin D, Burdin M: Exhaled carbon monoxide in mechanically ventilated critically ill patients: influence of inspired oxygen fraction. Intensive Care Med 2000, 26(9):|228-3|.

14. Schober P, Kalmanowicz M, Loer SA: Effects of inspiratory oxygen concentration on endtidal carbon monoxide concentration. I Clin Monit Comput 2006, 20(2):89-94.

15. Adachi T, Hirota K, Hara T, Sasaki Y, Hara Y: Exhaled carbon monoxide levels change in relation to inspired oxygen fraction during general anesthesia. Anesth Analg 2007, 105(3):696-9.

16. Coburn RF, Forster RE, Kane PB: Considerations of the physiological variables that determine the blood carboxyhaemoglobin concentration in man. J Clin Invest 1965, 44: 1899-910.
17. Cope KA, Watson MT, Foster M, Sehnert SS, Risby TH: Effects of ventilation on the collection of exhaled breath in humans. $J$ Appl Physiol 2004, 96(4): I37I-9.

18. Harren FJM, Cotti G, Oomens J, Lintel Hekkert S: Photoacoustic spectroscopy in trace gas monitoring. In Encyclopedia of Analytical Chemistry John Wiley \& Sons Ltd. Chichester; 2000:2203-26. [RA Meyers (Series Editor)]

19. Taskar V, John J, Larsson A, Wetterberg T, Jonson B: Dynamics of carbon dioxide elimination following ventilator resetting. Chest 1995, 108(I): 196-202

20. Jarvis MJ, Belcher M, Vesey C, Hutchison DCS: Low cost carbon monoxide monitors in smoking assessment. Thorax 1986, 4 I (II):886-7.

21. Khambatta HJ, Sullivan SF: Carbon dioxide production and washout during passive hyperventilation alkalosis. I Appl Physiol 1974, 37(5):665-9.

22. Mohan OE, Cooper DM, Jensen SC, Armon Y, Landaw EM: $\mathbf{C O}_{2}$ washout kinetics in acute hypercapnia. Respir Physiol 1991, 86(2): $159-70$

23. Coburn RF: The carbon monoxide body stores. Ann NY Acad Sci 1970, I74(I): II-22.

24. Fowle AS, Matthews CM, Campbell EJ: The rapid distribution of $\mathrm{H}_{2} \mathrm{O}$ and $\mathrm{CO}_{2}$ in the body in relation to the immediate carbon dioxide storage capacity. Clin Sci 1964, 27:5I-65.

25. Zetterquist $W$, Marteus $H$, Johannesson $M$, Nordval SL, Ihre $E$ : Exhaled carbon monoxide is not elevated in patients with asthma or cystic fibrosis. Eur Respir J 2002, 20(I):92-9.

26. Togores B, Bosch M, Agustí AGN: The measurement of exhaled carbon monoxide is influenced by airway obstruction. Eur Resp J 2000, I 5(I): 177-80

27. Deveci SE, Deveci F, Açik Y, Ozan AT: The measurement of exhaled carbon monoxide in healthy smokers and nonsmokers. Respir Med 2004, 98(6):55I-6.

28. Carpagnano GE, Kharitonov SA, Foschino-Barbaro MP, Resta $O$ Barnes PJ: Increased inflammatory markers in the exhaled breath condensate of cigarette smokers. Eur Respir J 2003, 2I (4):589-93.

29. Yamaya M, Sekizawa K, Ishizuka S, Monma M, Mizuta K, Sasaki H: Increased Carbon Monoxide in Exhaled Air of Subjects with Upper Respiratory Tract Infections. Am J Respir Crit Care Med 1998, 158:3|I-3|4.

30. Zayasu K, Sekizawa K, Okinaga S, Yamaya M, Ohrui T, Sasaki H Increased Carbon Monoxide in Exhaled Air of Asthmatic Patients. Am J Respir Crit Care Med 1997, I 56: I I 40-I I 43.

31. Paredi P, Shah PL, Montuschi P, Sullivan P, Hodson ME, Kharitonov SA, Barnes PJ: Increased carbon monoxide in exhaled air of patients with cystic fibrosis. Thorax 1999, 54:917-920.

32. Horváth I, Loukides S, Wodehouse T, Csiszér E, Cole PJ, Kharitonov SA, Barnes PJ: Comparison of exhaled and nasal nitric oxide and exhaled carbon monoxide levels in bronchiectatic patients with and without primary ciliary dyskinesia. Thorax 2003, 58(I):68-72.

33. De las Heras $D$, Fernández J, Ginès $P$, Cárdenas $A$, Ortega $R$, Navasa M, Barberá JA, Calahorra B, Guevara M, Bataller R, Jiménez W, Arroyo $V$, Rodés J: Increased carbon monoxide production in patients with cirrhosis with and without spontaneous bacterial peritonitis. Hepatology 2003, 38(2):452-9.

34. Cunnington AJ, Hormbrey P: Breath analysis to detect recent exposure to carbon monoxide. Postgrad Med I 2002, 78(9|8):233-7.

35. Laranjeira R, Pillon S, Dunn J: Environmental tobacco smoke exposure among nonsmoking waiters: measurement of expired carbon monoxide levels. Sao Paulo Med J 2000, I I 8(4):89-92.

36. Scharte M, Bone HG, Van Aken H, Meyer J: Increased carbon monoxide in exhaled air of critically ill patients. Biochem Biophys Res Commun 2000, 267(I):423-6.

\section{Pre-publication history}

The pre-publication history for this paper can be accessed here:

http://www.biomedcentral.com/1471-2466/9/51/prepub 